\title{
GEOSPATIAL ANALYSIS OF THE DISTRIBUTION OF AIR POLLUTANT EMISSIONS IN TEHRAN WITH A FOCUS ON ENVIRONMENTAL JUSTICE
}

\author{
Sareh Ghorbani ${ }^{1}$, Esmail Salehi ${ }^{*}$, Shahrzad Faryadi ${ }^{3}$, Hamid Reza Jafari ${ }^{4}$ \\ ${ }^{1}$ University of Tehran, Graduate Faculty of Environment, Tehran, Iran; \\ ${ }^{2 *}$ Associate Professor of Department of Environmental Management Planning University of Tehran, Tehran, Iran; \\ ${ }^{3}$ University of Tehran, Department of Environmental Management Planning, Tehran, Iran; \\ ${ }^{4}$ University of Tehran, Department of Environmental Management Planning, Tehran, Iran;
}

*Corresponding author Esmail Salehi, email: e.salehi@aftermail.ir;

Received January 2020; Accepted February 2020; Published March 2020;

DOI: https://doi.org/10.31407/ijees10.201

\begin{abstract}
Despite its environmental and social benefits, urban development has also led to severe problems such as air pollution, especially in megacities with escalating population growth like Tehran, the capital of Iran. This study aims to analyze the spatial correlation between air pollutants' emission and the socioeconomic status of urban districts, with an emphasis on environmental justice, in order to make a contribution to the quantitative analysis of environmental inequalities in Tehran. Thus, a quantitative spatial analysis was carried out by a geographically weighted regression model in order to compare the relationship between the emission of air pollutants from mobile and stationary sources in selected urban districts and the socioeconomic status of these districts. The results showed that, of all the 22 districts of Tehran, district 3 had the highest and district 18 the lowest rank in terms of socioeconomic status. It was concluded that districts with better socioeconomic statuses emit more pollutants, while they are less exposed to the subsequent risks, which implies environmental injustice in the study area.
\end{abstract}

Key words: Urban Equity, Environmental inequality, Air pollution, Geographically Weighted Regression, Socioeconomic status. 